\title{
LIBERALISMO POLÍTICO, JUSTIFICACIÓN PÚBLICA Y VERDAD *
}

\author{
Mariano Garreta Leclercq \\ Universidad de Buenos Aires-Conicet
}

RESUMEN. Según J. RAWLS, como consecuencia del hecho del pluralismo razonable, el criterio de corrección de las concepciones políticas de la justicia no debe ser el concepto de verdad, sino la idea de razonabilidad. RawLS ha sostenido, además, que el liberalismo político prescinde del concepto de verdad. Recientemente, J. COHEN ha defendido, contra RAWLS, la idea de que el liberalismo político no puede ni debe prescindir del concepto verdad, éste debe formar parte de la razón pública de las democracias. La meta del presente artículo es demostrar que el concepto de verdad, en particular, dada su conexión con el concepto de justificación, puede ser utilizado como base para impugnar algunas de las metas fundamentales del proyecto del liberalismo político. En la sección final del artículo se propone una defensa del liberalismo político a partir de una reinterpretación de algunos de sus conceptos básicos que haría viable y deseable, contra la posición de COHEN, el intento rawlsiano de evitar el uso del concepto de verdad.

Palabras clave: liberalismo político, verdad, justificación, creencia, aceptación.

ABSTRACT. According to J. RAWLS, in response to the fact of reasonable pluralism, the criterion of correction in conceptions of justice should not be the concept of truth, but the idea of the reasonable. RawLs has also stated that political liberalism does without the concept of truth. J. COHEN has recently sustained against RAWLS that political liberalism cannot and should not leave out the concept of truth: in fact, it must be part and parcel of public reason in any democracy. The aim of the present paper is to prove that the concept of truth, in particular in view of its connection with the concept of justification, can be used as a basis to challenge some of the fundamental goals of political liberalism. The final part of the paper posits a defence of political liberalism through a reinterpretation of some of its fundamental concepts that makes the Rawlsian attempt to avoid the use of the concept of truth feasible and desirable, against COHEN's stance.

Keywords: political liberalism, truth, justification, belief, acceptance.

* Fecha de recepción: 10 de enero de 2010. Fecha de aceptación: 12 de febrero de 2010.

Una versión preliminar del presente artículo fue expuesta en las Terceras Jornadas CIF-SADAF, las cuales fueron organizadas por el Centro de Investigaciones Filosóficas y la Sociedad Argentina de Análisis Filosófico y tuvieron lugar en Buenos Aires los días 25, 26 y 27 de marzo de 2010. Agradecemos los comentarios críticos de los asistentes, en particular de Luciano Venezia — quien fue designado por los organizadores para discutir la ponencia-, Osvaldo Guariglia, Marcelo Alegre, Eduardo Rivera López, Eleonora Orlando y Julio Montero. De igual modo, agradecemos las sugerencias de un evaluador anónimo de la revista Doxa. 


\section{INTRODUCCIÓN}

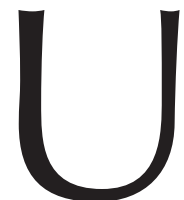

na de los rasgos característicos del liberalismo político rawlsiano consiste en la tesis de que la razonabilidad, y no la verdad, constituye el criterio de corrección de las concepciones políticas de la justicia ${ }^{1}$. El liberalismo político «no usa [...] ni niega el concepto de verdad; tampoco pone en cuestión ese concepto, ni podría decir que el concepto de verdad coincide con su idea de lo razonable. Ocurre más bien que, dentro de sí misma, la concepción política prescinde del concepto de verdad $\gg^{2}$. La apelación a la verdad quedaría, por así decirlo, restringida al ámbito en que se desarrollan las distintas doctrinas comprehensivas de orden religioso, filosófico o moral que coexisten en el seno de las sociedades democráticas $^{3}$; es decir, quedaría en manos de los ciudadanos, no cuando actúan en la arena política, sino cuando lo hacen en contextos no políticos (por ejemplo, en el contexto de asociaciones de la sociedad civil, como las iglesias). J. COHEN ha sostenido en un reciente trabajo que esta posición de RAWLS conduce a un serio dilema: podemos tener el concepto de verdad o bien podemos tener razón pública, pero no ambas cosas a la vez ${ }^{4}$. COHEN afirma que la posición de RAWLS acarrea serias dificultades para el liberalismo político. Por una parte, torna la idea de razón pública «innecesariamente contenciosa, como si estuviese comprometida con el punto de vista de que la verdad acerca de la justicia no tiene importancia». Por otra parte, «torna la idea de razón pública difícil de comprender, porque ella presupone dejar de lado el concepto de verdad, mientras se preservan las nociones de creencia, aserción, juicio, razón y objetividad» ${ }^{5}$. La tesis de COHEN es que si se apela a tales nociones, como de hecho lo hace RAWLS, debería admitirse que el concepto de verdad ya está en juego en la razón pública: las nociones de creencia, aserción, juicio, razón y objetividad son inseparables del concepto de verdad ${ }^{6}$.

La objeción del autor a la posición rawlsiana podría ser descrita como una crítica interna. Como acabamos de ver, éste rechaza la idea de que la concepción política de la justicia pueda prescindir del concepto de verdad y afirma que dicho concepto tiene un rol legítimo y significativo que jugar en el argumento político público. Sin embargo, esto no implica rechazar el liberalismo político; COHEN afirma que la concepción de la verdad que debe jugar un papel en la justificación pública debe ser ella misma política: su propuesta consiste en acuñar una concepción política de la verdad ${ }^{7}$. Además, el autor suscribe los rasgos fundamentales del ideal de razón pública tal como han sido formulados por RAWLS y se abstiene de cuestionar la tesis de que el criterio de corrección de las concepciones políticas de la justicia sea la razonabilidad.

1 Cfr. RaWLS, 1993: 127.

2 RAWLS, 1993: 94.

3 RAWLS, 1993: 116. Una doctrina es «comprehensiva» cuando incluye «concepciones sobre qué es de valor en la vida humana, e ideales sobre el carácter personal tanto como ideales de amistad, relaciones familiares y de asociación, y otros muchos elementos que conforman nuestra conducta y, finalmente, nuestra vida considerada en forma global» (RAWLS, 1993: 13). RAWLS distingue, también, entre doctrinas plena y parcialmente comprehensivas. Las plenamente comprehensivas abarcan todos los valores y virtudes en un sistema articulado en forma precisa. Una concepción es parcialmente comprehensiva si se limita a incluir algunos valores y virtudes no políticos, y su articulación es menos detallada y abarcadora.

4 Cfr. COHEN, 2009: 5.

5 COHEN, 2009: 5.

Cfr. COHEN, 2009: 23.

7 Cfr. CoHen, 2009: 3. 
COHEN parece estar en lo cierto al afirmar que el concepto de verdad se encuentra estrechamente relacionado con otras nociones de las que el liberalismo político no puede prescindir, como las de creencia, aserción y juicio - y también, como veremos, con la noción de justificación-. Sin embargo, ¿está en lo correcto al suponer, contra RAWLS, que eso hace del concepto de verdad una categoría ineliminable y, en cierta forma, fundamental en el proceso de justificación política? ¿La apelación al concepto de verdad en el proceso de justificación pública de propuestas políticas es realmente aproblemática para el proyecto del liberalismo político?

Como primer paso para abordar estas preguntas es necesario analizar la formulación rawlsiana del concepto de razonabilidad. A partir del análisis de este concepto reconstruiremos el argumento fundamental por el cual RAWLS intenta justificar su tesis de que las doctrinas comprehensivas religiosas, filosóficas o morales no pueden constituir una base pública de justificación en el contexto de pluralismo ideológico que ofrecen las democracias contemporáneas (I.1). Intentaremos demostrar que dicho argumento posee significativas deficiencias y que ellas se encuentran vinculadas, en última instancia, con el uso del concepto de verdad (I.2). Luego examinaremos el concepto de justificación al que apela explícitamente RAWLS en sus obras y demostraremos que éste resulta incompatible con una concepción epistémica estándar de la justificación de creencias, lo cual, según sostendremos, representa un problema significativo para el liberalismo político (I.3). Por último, propondremos una estrategia de reformulación y de defensa del liberalismo político que aspira a superar las dificultades planteadas (II).

\section{I.}

1.

Comencemos por examinar el concepto de razonabilidad. Aunque la pluralidad de usos del término «razonable» en los textos de RAWLS es muy amplia ${ }^{8}$, su significado fundamental parece estar dado por la concepción de persona razonable ${ }^{9}$. Dicha concepción posee tres rasgos fundamentales. En primer lugar, RAWLS atribuye a las personas razonables dos facultades morales: un sentido de justicia, esto es, la capacidad de comprender, aplicar y actuar con arreglo a una concepción de la justicia, y la capacidad de poseer una concepción del bien, que implica la aptitud para formular, perseguir racionalmente y revisar una concepción del bien ${ }^{10}$. Además, las personas cuentan con las capacidades intelectuales de juicio, pensamiento e inferencia, poseen una concepción del bien determinada que interpretan a la luz de una doctrina comprehensiva y

8 RAWLS habla, para citar algunos ejemplos, de principios de justicia razonables, juicios razonables, personas razonables, concepciones comprehensivas razonables, fe razonable, la virtud de la razonabilidad, justificación pública razonable, pluralismo razonable, creencia razonable, psicología moral razonable, duda razonable, desacuerdo razonable, norma razonable, expectativas razonables, variante razonable de una concepción política de la justicia, etcétera.

9 En este punto seguimos la interpretación propuesta por L. WeNAR ( $f f r$. WeNAR, 1995). S. FreEMAN también sostiene que el concepto de persona razonable tiene un carácter seminal y constituye el punto focal para interpretar otros usos de la idea de razonabilidad ( $c f r$. FREEMAN, 2007: 346).

${ }_{10}$ Cfr. RAWLS, 1993: 50-52. 
son capaces de ser miembros plenamente cooperativos de la sociedad durante una vida completa ${ }^{11}$. En segundo lugar, las personas razonables poseen la disposición de proponer principios y términos justos de cooperación social, y de cumplir con ellos, siempre y cuando los demás sujetos también lo hagan ${ }^{12}$. Como sostiene RAWLS:

«Las personas son razonables en un aspecto básico cuando, digamos, entre iguales, se encuentran dispuestas a proponer principios y criterios como términos equitativos de cooperación y a aceptarlos de buena gana, siempre que se les asegure que los demás harán lo mismo. Las personas conciben esas normas como razonablemente aceptables para todos y, por tanto, como justificables para todos; y están dispuestas a discutir los términos equitativos de cooperación que otros propongan» ${ }^{13}$.

En tercer lugar, las personas razonables reconocen las cargas del juicio (burdens of judgment) y sus consecuencias para la justificación pública del uso del poder legítimo del Estado ${ }^{14}$. Las cargas del juicio constituyen, según RAWLS, las fuentes del desacuerdo razonable, y hacen referencia a «las muchas dificultades involucradas en el ejercicio correcto (y conciente) de nuestros poderes de razón y juicio en el curso ordinario de la vida política» ${ }^{15}$. Aunque el autor no pretende ofrecer una lista completa, algunas de las cargas del juicio más importantes son las siguientes.

«- Las evidencias relevantes - empíricas o científicas - que deben ser analizadas son conflictivas y complejas y, por consiguiente, difíciles de establecer y evaluar.

- Aun cuando estemos de acuerdo acerca del tipo de consideraciones que son relevantes para el caso en discusión, podemos disentir en relación con su peso e importancia y llegar a distintos juicios.

- Casi la totalidad de los conceptos que utilizamos, no sólo los morales y políticos, son vagos y requieren de juicio e interpretación (y juicio e interpretación de esos juicios e interpretaciones), lo que conduce a desacuerdos.

- El modo en que las personas evalúan y sopesan las evidencias y valores se halla estructurado en cierta medida por su particular experiencia de vida. Como subraya RAWLS: "En una sociedad moderna, con los numerosos cargos y posiciones que acarrea, con su diversa división del trabajo, sus muchos grupos sociales y su variedad étnica, las experiencias globales de los ciudadanos son suficientemente dispares como para que sus juicios sean, al menos en cierto grado, divergentes en muchos si no en la mayoría de los casos que presentan una complejidad significativa" ${ }^{16}$.

- Existen genuinos dilemas morales en los que diferentes tipos de consideraciones normativas, usualmente opuestas y dotadas de un peso considerable entran en juego.

- Las sociedades deben realizar una selección de un número limitado de valores entre todos los que podrían ser realizados (selección que puede llevar a profundos conflictos)».

Tomar conciencia de las implicaciones de estas dificultades que afectan nuestros juicios tanto valorativos como teóricos conducirá a reconocer uno de los hechos básicos que toma como punto de partida el liberalismo político: la idea de que «muchos de nuestros juicios más importantes son realizados bajo condiciones en las cuales no

11 Cfr. RAWLS, 1993: 15-35.

12 Cfr. RAWLS, 1993: 48-54.

13 RAWLS, 1993: 49.

14 Cfr. RAWLS, 1993, 54-58. RAWLS también atribuye a las personas razonables otras dos características: contar con una psicología moral razonable ( $c f r$. RAWLS, 1993: 81-86) y reconocer los elementos esenciales de una concepción de la objetividad ( $c f r$. RAWLS, 1993: 110-112).

15 RAWLS, 1993: 56.

16 RAWLS, 1993: 56-57. 
puede tenerse la expectativa de que personas con plenos poderes de razón, incluso tras una discusión libre, lleguen unánimemente a una misma conclusión» ${ }^{17}$. Como afirma RAWLS, en el caso de las ciencias naturales resulta plausible esperar, al menos a largo plazo, que nuestro intento conciente de razonar unos con otros conducirá a un acuerdo razonable ${ }^{18}$. Sin embargo, las cargas del juicio explicarían el hecho de que esta expectativa resulte infundada cuando discutimos, en la arena política de las democracias contemporáneas, el tipo de cuestiones que abordan las doctrinas comprehensivas.

Ahora bien, dado el segundo rasgo del concepto de persona razonable, los ciudadanos poseen un deseo básico de justificar sus acciones y propuestas políticas ante los demás, sobre la base de razones que ellos no puedan rechazar razonablemente ${ }^{19}$. Tomar conciencia de las implicaciones de las cargas del juicio conllevaría reconocer que el rechazo de nuestras propuestas políticas basadas en doctrinas comprehensivas por parte de otros agentes es una prueba de que hemos fallado en justificar dichas propuestas sobre la base de razones que los otros no puedan rechazar razonablemente. Como afirma RAWLS, «las personas razonables se dan cuenta de que las cargas del juicio ponen límites a lo que puede ser razonablemente justificado frente a otros» ${ }^{20}$. Aunque las cargas del juicio no impliquen, según subraya RAWLS, argumento alguno en favor de la duda y la incertidumbre, ni mucho menos del escepticismo ${ }^{21}$, conducirían a reconocer que la afirmación de que nuestras creencias comprehensivas son verdaderas es una pretensión que nadie está en condiciones de justificar, en forma general, frente al resto de sus conciudadanos en el marco del debate político ${ }^{22}$. Según RAWLS:

«Una base de justificación pública y compartida que se aplique a las doctrinas comprehensivas está ausente en la cultura pública de una sociedad democrática. Pero se necesita de esa clase de base para marcar la diferencia, en formas aceptables para un público razonable, entre creencias comprehensivas como tales y creencias comprehensivas verdaderas. [...] Por supuesto, aquellos que insisten en sus creencias también insisten en que sólo ellas son verdaderas: las imponen porque, afirman, sus creencias son verdaderas y no porque son sus creencias. Pero ésa es una pretensión que todos podrían tener, y es, además, una pretensión que nadie está en condiciones de justificar (that cannot be made good) frente a los ciudadanos en general» ${ }^{23}$.

Una vez aceptado esto, si queremos cumplir con el compromiso de buscar principios políticos que se encuentren apropiadamente justificados frente a todos los ciudadanos, deberemos considerar: 1) que hay buenas razones para suscribir una estructura institucional que garantice la tolerancia y la libertad de conciencia y pensamiento, y 2) que «no hay, entonces, razón alguna por la que cualquier ciudadano, o asociación de ciudadanos, debiera tener derecho a usar el poder político estatal para decidir acerca de esencias constitucionales o cuestiones de justicia básica según las directrices de la doctrina comprehensiva propia de esa persona o asociación» ${ }^{24}$. En lugar de apelar a doctrinas comprehensivas, los ciudadanos, los candidatos políticos, los legisladores y

\footnotetext{
17 RAWLS, 1993: 58.

18 Cfr. RaWLS, 1993: 55.

19 Cfr. RaWLS, 1993: 49, $n 2$.

20 RAWLS, 1993: 61.

21 Cfr. RaWLS, 1993: 63.

22 Cfr. RaWLS, 1993: 61.

23 RAWLS, 1993: 60-61.

24 RAWLS, 1993: 62.
} 
los funcionarios deberían elaborar concepciones políticas de la justicia y proceder a desarrollar y justificar sus propuestas a partir de ellas. Las concepciones políticas de la justicia se caracterizan por tres rasgos. En primer lugar, aunque son concepciones morales, han sido construidas para ser aplicadas a un objeto específico, la estructura básica de una sociedad democrática. En segundo lugar, aceptar una concepción semejante no supone, a su vez, aceptar alguna doctrina comprehensiva religiosa, filosófica o moral particular. En tercer lugar, dichas concepciones están formuladas, hasta donde es posible, solamente en términos de ideas fundamentales pertenecientes o implícitas en la cultura política compartida de la comunidad y que, por lo tanto, resultan familiares y aceptables para todos los ciudadanos ${ }^{25}$.

\section{2.}

Como acabamos de ver, RAWLS deriva del concepto de persona razonable un argumento en favor de las ideas fundamentales del liberalismo político. ¿Se trata realmente de un buen argumento? Intentaremos demostrar que éste posee algunas deficiencias significativas. Dichas deficiencias tienen su origen en el concepto de justificación y, en última instancia, en los vínculos que hay entre tal concepto y el de verdad.

El núcleo del argumento de RAWLS, que fue reconstruido páginas atrás, consiste en la idea de que debemos reconocer que las doctrinas comprehensivas religiosas, filosóficas o morales no constituyen una base pública, es decir, una base apropiada, de justificación de nuestras propuestas políticas. $\mathrm{Al}$ apelar exclusivamente ${ }^{26}$ a doctrinas comprehensivas en la justificación de las políticas fundamentales del Estado ${ }^{27}$, fallamos en cumplir con la obligación moral fundamental, derivada de nuestro carácter de personas razonables, de justificar nuestras propuestas sobre la base de razones que los otros no puedan rechazar razonablemente. Fallamos en justificar, frente a los otros ciudadanos, nuestras creencias, dado que, como afirma RAWLS, no somos capaces de establecer una distinción pública «entre creencias comprehensivas como tales y creencias comprehensivas verdaderas». Si interpretamos este argumento a la luz de lo que podríamos denominar una concepción estándar de la noción de justificación epistémica (en adelante CEE), surge una serie de dificultades. ¿Qué significa justificar una creencia? Desde una perspectiva estándar o tradicional la respuesta es que justificar la creencia de que $p$, equivale a ofrecer una explicación adecuada de la verdad de que $p$. Una explicación de la verdad de una proposición es adecuada cuando se apoya: $a$ ) en formas de razonar correctas, y $b$ ) en evidencias pertinentes y accesibles para todo su-

${ }^{25}$ Cfr. RAWLS, 2001: 26-27. RAWLS introduce otros tres rasgos adicionales que dan cuenta del carácter específicamente liberal de las concepciones políticas de la justicia: dichas concepciones: a) enumeran derechos y libertades básicas del tipo familiar para un régimen constitucional; $b$ ) asignan a esos derechos y libertades una prioridad especial, particularmente con respecto a los reclamos basados en la apelación al bien común y los valores perfeccionistas, y c) aseguran para todos los bienes primarios necesarios para volver a los ciudadanos capaces de hacer un uso efectivo e inteligente de sus libertades ( $c f r$. RAWLS, 1999: 14).

26 RAWLS, en realidad, no rechaza la apelación en el curso del debate político a doctrinas comprehensivas; el punto es que debe cumplirse una cláusula proviso: en algún momento del debate, los agentes deben dar una justificación política de sus propuestas, es decir, una justificación que no dependa de la aceptación de la doctrina comprehensiva que el agente suscribe ( $c f r$. RAWLS, 1999a: 584).

27 Es decir, aquellas que afectan las esencias constitucionales o las cuestiones de justicia básica. 
jeto con capacidades cognitivas normales ${ }^{28}$. Cuando disponemos de una justificación apropiada podemos concluir que la probabilidad de que nuestras creencias sean verdaderas debe ser mayor que la probabilidad de que creencias injustificadas alternativas lo sean ${ }^{29}$.

Cuando RAWLS afirma que, apelando a doctrinas comprehensivas en la esfera pública, no es posible establecer una diferencia entre creencias puramente subjetivas, de las que no podemos predicar verdad, y creencias verdaderas, está diciendo que nuestras creencias comprehensivas no están epistémicamente justificadas. Ello se debe a que estar justificado, de acuerdo con CEE, presupone disponer de una explicación apropiada de la verdad de una creencia y ello equivale, justamente, a poder establecer una diferencia, basada en buenas razones, entre creencias puramente subjetivas y creencias que pueden ser caracterizadas como verdaderas. Este resultado es incompatible con el explícito rechazo del escepticismo o de cualquier cuestionamiento del grado de seguridad con el que los agentes afirman sus doctrinas comprehensivas que caracteriza al liberalismo político ${ }^{30}$. Si no estamos justificados a afirmar que nuestra doctrina comprehensiva es verdadera en la arena política, ¿por qué deberíamos estarlo en otros contextos? El liberalismo político parece requerir, para evitar esta objeción, la apelación a una suerte de contextualismo de la justificación. Los agentes deberían poder estar justificados en afirmar que $p$, esto es, una doctrina comprehensiva religiosa, filosófica o moral determinada, en un contexto no político, C1, y no estar justificados a afirmar que $p$ en C2, la esfera política. Esta posición contextualista parece incompatible CEE: desde dicha perspectiva, estar justificados a creer que $p$ implica que estamos en condiciones de afirmar que la probabilidad de que la proposición $p$ sea verdadera es superior a la de que sean verdaderas cualesquiera otras proposiciones $q, r, s \ldots$ que carezcan de justificación. La noción de «probabilidad de ser verdadero» no parece apta para ser interpretada en clave contextualista. Supongamos que las creencias $q, r$ y $s$ no están justificadas en ningún contexto. Si un agente puede afirmar que está justificado a creer que $p$ en $\mathrm{C} 1$, pero no en C2, ello implica que el sujeto está diciendo, al mismo tiempo, que $p$ tiene una probabilidad mayor de ser verdadera que las creencias $q, r$ y $s$ — dado que $p$ está justificada en $\mathrm{C} 1$ - y que $p$ no dispone de una probabilidad mayor de ser verdadera que $q, r$ y $s$-dado que $p$ no puede ser justificada en C2—. Dicha

${ }^{28}$ Cfr. RAz, 1990: 32. R. FumerTON apela a una idea similar al intentar ofrecer una definición de «justificación» neutral entre las distintas concepciones que pueden encontrarse en epistemología. Según el autor, al margen de lo que pueda agregarse a la definición de justificación epistémica de nuestra creencia en una proposición, una justificación debe caracterizarse por hacer probable la verdad de la proposición que es objeto de creencia ( $c f r$. FUMERTON, 2002: 205).

29 Cfr. FumERTON, 2002: 205. Como señala L. BonJour resumiendo esta posición: «La función básica de la justificación consiste en ser un medio para la verdad, en establecer un vínculo más directo y asequible entre nuestro punto de partida subjetivo y nuestra meta objetiva [...] Si la justificación epistémica no fuera conductiva a la verdad de este modo, si encontrar creencias epistémicamente justificadas no incrementara substancialmente la probabilidad de hallar las verdaderas, entonces la justificación epistémica sería irrelevante para nuestra principal meta cognitiva y de dudoso valor. Sólo si tenemos razones para pensar que la justificación epistémica constituye un camino a la verdad, tenemos, como seres cognitivos, algún motivo para preferir creencias epistémicamente justificadas a creencias epistémicamente injustificadas» (BONJouR, 1985: 7-8).

${ }^{30}$ RAWLS afirma que el liberalismo político: «[...] no cuestiona que muchos juicios políticos y morales sean correctos, y entiende que varios son razonables. Tampoco pone en cuestión la posible verdad de cuestiones de fe. Sobre todo, no argumenta en favor de la duda y de la incertidumbre, ni mucho menos del escepticismo, en relación con nuestras creencias [comprehensivas]» (RAWLS, 1993: 63). La cursiva es nuestra. 
posición no puede ser plausible, o bien $p$ tiene mayor probabilidad de ser verdadera que otras proposiciones, como $q, r$ y $s$, no justificadas ni en $\mathrm{C} 1$ ni en $\mathrm{C} 2$, o no la tiene en absoluto. Podemos, por tanto, concluir que el argumento de RAWLS no funciona. Si un agente puede estar epistémicamente justificado en creer en su doctrina comprehensiva en contextos no políticos, también debería poder estarlo en contextos políticos. Siguiendo la misma lógica, si un agente debiera reconocer que ha fallado en ofrecer una justificación epistémica adecuada de su doctrina comprehensiva en la esfera política, debería reconocer que ha fallado también en contextos no políticos ${ }^{31}$. De modo que si el argumento de RAWLS hiciera lo que afirma hacer, es decir, probar que la apelación a doctrinas comprehensivas es incompatible con la posibilidad de ofrecer una justificación apropiada de nuestras creencias en la esfera política, equivaldría a cuestionar las pretensiones de aquellos que creen que la doctrina comprehensiva que suscriben es verdadera o correcta. Esta conclusión es incompatible con el rechazo del escepticismo respecto de las doctrinas comprehensivas que asume el liberalismo político.

Es posible analizar la cuestión desde otra perspectiva. Como sabemos, RAWLS sostiene que las doctrinas comprehensivas no constituyen una base apropiada de justificación en la esfera política. Ello se debería a que en dicha esfera no existe un trasfondo (background) común de prácticas y experiencias compartidas que permita distinguir entre creencias comprehensivas puramente subjetivas y creencias cuya verdad pueda ser afirmada sobre la base de buenas razones. Las drásticas diferencias de educación, herencia cultural, experiencias vitales, etc., que pueden ser encontradas en una sociedad plural hacen que lo que para un sujeto o grupo cuenta como una evidencia o una razón suficiente para adoptar una creencia comprehensiva, carezca de todo peso para otros agentes. Lo que para unos es una evidencia o una razón adecuada puede resultar, incluso, inaccesible para otros agentes que no disponen de la experiencia vital o de la educación requerida ${ }^{32}$. Por supuesto, nadie puede exigir a los otros pasar por un proceso de reeducación —que, además, muchas veces ni siquiera es posible- para que comprendan los méritos del punto de vista que defiende. De modo que la justificación pública de creencias comprehensivas no resultaría viable en la arena política. Ahora bien, un crítico del liberalismo político puede aducir que lo que parece establecer esta línea de argumentación es una imposibilidad práctica contingente que carece de relevancia cognitiva y que no permite inferir la conclusión deseada, es decir, que en esas condiciones de pluralismo los agentes hayan, necesariamente, fallado en justificar sus puntos de vista comprehensivos frente a aquellos interlocutores que rechazan sus propuestas. Lo que probaría el argumento de RAWLS, en el mejor de los casos, es que las doctrinas comprehensivas no son una base adecuada para convencer o persuadir a

31 Por supuesto, si al pasar de un contexto a otro, por ejemplo, del no político al político, el agente descubriera alguna evidencia relevante de que $p$ no es una creencia verdadera, habría buenas razones para que concluya que no está, contra lo que creía antes, justificado en afirmarla, pero esas mismas razones deberían, si el agente es racional, conducirlo a mantener esa conclusión al pasar nuevamente al contexto no político.

32 Esto es lo que pone en evidencia la cuarta carga del juicio enumerada por RAWLS. Dicha carga del juicio, como sostiene Ch. LARMORE, juega un papel decisivo en su explicación del hecho de pluralismo razonable. Según LARMORE, dado que la mayoría de las cargas del juicio citadas por RAWLS no tienen una conexión especial con el razonamiento acerca de valores, resultan insuficientes para explicar el pluralismo de las democracias contemporáneas. LARMORE afirma, plausiblemente a mi juicio, que «la gran variedad de experiencias de vida creadas por la sociedad moderna, con su compleja división del trabajo y su rica herencia de muchas tradiciones culturales diferentes, ofrece la clave para explicar el fenómeno» (LARMORE, 1996: 170). 
otros ciudadanos de que una propuesta política está apropiadamente justificada. Sin embargo, ello no equivale a demostrar que las doctrinas comprehensivas no puedan constituir una base pública de justificación. Fallar en convencer o persuadir a otro sujeto de que $p$ está justificada, no equivale a fallar en justificar $p$ frente a ese sujeto.

El siguiente ejemplo ilustra el problema. Imaginemos que un físico le explica a un agente que carece de formación en dicha disciplina una teoría significativamente compleja que entra en contradicción con el sentido común. Supongamos que la teoría en cuestión es aceptada por la comunidad científica y que la explicación ofrecida por el físico es apropiada dado el grado de conocimiento del que dispone la disciplina en la actualidad. El interlocutor del científico no logra comprender la explicación y considera que la teoría de la que se le habla, dado que choca drásticamente con el sentido común, no puede ser verdadera. La posición que asume el interlocutor del científico se explica por el hecho de que éste no posee los conocimientos y habilidades requeridos para comprender la explicación que le es ofrecida. ¿Diríamos, en este caso, que el científico no dispone de una justificación apropiada de su teoría o que ha fallado en justificarla frente a su interlocutor? La respuesta a esta pregunta parece ser, a la luz de CEE, necesariamente negativa. Si, como estamos suponiendo, desde un punto de vista cognitivo la justificación ofrecida por el científico no presenta falla alguna, no parece haber ninguna razón para concluir que el científico haya fracasado en justificar la teoría en cuestión frente a su interlocutor. El hecho de que haya fallado en persuadirlo no implica que haya fallado en ofrecer una explicación plausible y públicamente accesible de la verdad de su posición. Después de todo, si su interlocutor dispusiera de los conocimientos requeridos hubiera debido comprender y aceptar la teoría en cuestión. No hay ningún obstáculo insalvable para que el agente adquiera tales conocimientos. La justificación ofrecida es perfectamente pública y accesible para todo sujeto con capacidades cognitivas normales ${ }^{33}$. Aunque de hecho un agente particular no sea capaz de comprender una justificación ello no implica que haya habido un defecto en ella. Para que pueda afirmarse tal cosa es necesario que existan errores lógicos en los razonamientos empleados, que no se haya tomado en cuenta evidencia relevante y disponible o que se apelara a evidencias que no fueran públicamente accesibles. Estamos suponiendo que nada de eso ocurre en caso del científico. Según muestra el ejemplo, desde la perspectiva de CEE, estar justificado a creer que $p$, equivale a estar justificado a afirmar que $p$ frente a todo agente dotado de capacidades cognitivas normales (ello es así porque la justificación debe apelar a razones y evidencias públicamente accesibles). Por supuesto, estar justificado frente a otro sujeto a afirmar que $p$ no garantiza que un agente sea, en la práctica, capaz de persuadirlo de que crea que $p$ es verdadera.

Ahora bien, ¿el caso del científico es realmente diferente al de un agente que defiende una doctrina comprehensiva en la esfera política? Está claro que las doc-

33 Disponer de una justificación, cuando se interpreta este concepto en términos epistémicos, es siempre disponer de una justificación pública. Como sostiene J. RAZ: «Las justificaciones son en principio públicamente disponibles. Puede haber razones contingentes por las cuales esta persona o aquélla pueden encontrar muy difícil llegar a reconocer que los principios están justificados. Pero no hay nada inherentemente privado acerca de la justificación» (RAZ, 1998: 37). Si la justificación en la que se apoyan las creencias de un sujeto - ya sean evidencias, razonamientos, etc. - no fueran accesibles para todo agente, simplemente no contarían como una justificación en absoluto. La justificación es, por naturaleza, pública. 
trinas comprehensivas presentan diferencias significativas con las teorías científicas. Sin embargo, si se supone, como lo hace el liberalismo político, que las doctrinas comprehensivas son susceptibles de una justificación epistémica apropiada, debe suponerse también que es posible defenderlas apelando a argumentos válidos que no omitan evidencia relevante y que recurran a evidencia públicamente accesible (aunque no necesariamente accesible de hecho para todo agente) ${ }^{34}$. Esto vuelve la situación de un agente que argumenta en la esfera política a partir de su doctrina comprehensiva suficientemente similar al ejemplo del científico como para que puedan extraerse las mismas conclusiones. Si un agente dispone de una justificación epistémicamente apropiada de su punto de vista comprehensivo el persistente desacuerdo de algunos de sus interlocutores sólo prueba que ha fallado en persuadirlos, no que haya fallado en justificarlo frente a ellos.

El liberalismo político enfrenta un serio dilema. Si fuera posible concluir que el persistente desacuerdo en torno de las doctrinas comprehensivas prueba que al apelar a ellas los agentes fallan en ofrecer una justificación apropiada de sus creencias frente a sus interlocutores, tal cosa equivaldría a asumir el tipo de posición escéptica respecto de las doctrinas comprehensivas que el liberalismo político pretende evitar. Esta conclusión se apoya en el hecho de que no disponer de una justificación pública y accesible - es decir, una justificación que cuente como una justificación frente a los otrosequivale, tout court, a no disponer de una justificación epistémica apropiada. Si, por el contrario, se admite que los agentes pueden poseer, sobre la base de sus doctrinas comprehensivas, una justificación epistémica apropiada, entonces hay que reconocer que pueden cumplir con su obligación de justificar sus propuestas políticas frente a sus interlocutores apelando a esas creencias religiosas, filosóficas o morales, aun cuando no logren persuadirlos efectivamente de la verdad de sus puntos de vista. Cualquiera de los dos resultados es fatal para la propuesta rawlsiana.

\section{3.}

Parece posible ofrecer una respuesta a las objeciones precedentes apelando a la definición del concepto de justificación propuesta por RAWLS. Según el autor:

«Justificación es argumentación dirigida a aquellos que están en desacuerdo con nosotros, o a nosotros mismos cuando no logramos fijar una posición. Presupone el choque de puntos de vista entre personas o dentro de una persona, y aspira a convencer a otros, o a nosotros mismos de la razonabilidad de los principios sobre los cuales nuestras afirmaciones y juicios se encuentran fundados. Dado que su meta es la reconciliación por medio de la razón, la justificación procede a partir de aquello que todas las partes de la discusión suscriben en común. Idealmente, justificar una concepción de la justicia a otro sujeto es ofrecerle una prueba de sus principios que ambos aceptemos, teniendo esos principios consecuencias que concuerden con nuestros juicios considerados. Entonces, una mera prueba no es una justificación. Una prueba simplemente despliega las relaciones lógicas entre proposiciones. Pero las pruebas se convierten en justificaciones una vez que los puntos de partida son mu-

34 Si, por el contrario, negáramos esta posibilidad estaríamos asumiendo una posición escéptica acerca de las doctrinas comprehensivas que, como sabemos, el liberalismo político rechaza en forma explícita y enfática (cfr. RAWLS, 1993: 63). 
tuamente reconocidos, o las conclusiones son tan convincentes como para persuadirnos de la plausibilidad de la concepción expresada por las premisas» ${ }^{35}$.

Es importante subrayar que el concepto de justificación propuesto por RAWLS (que podríamos denominar CRJ) presenta significativas diferencias con CEE. En primer lugar, a diferencia de lo que ocurre en CEE, en CRJ el concepto de verdad no juega un papel relevante. Según CRJ, el objetivo de justificar una proposición no consiste en ofrecer una explicación plausible de la afirmación de que es verdadera, sino satisfacer la meta práctica de convencer a otros agentes que originalmente estaban en desacuerdo con nosotros de que acepten la proposición en cuestión. La meta es la «reconciliación» - que, obviamente, no es una categoría epistémica, sino práctica- por medio de la razón. No se trata, como afirma RAWLS al referirse al concepto de justificación en otro texto, de encontrar la posición «verdadera», sino aquella concepción que pueda «servir como una base de un acuerdo político informado y voluntario entre ciudadanos concebidos como personas libres e iguales» ${ }^{36}$. En segundo lugar, como consecuencia de la meta práctica que guía la búsqueda de justificación, el punto de partida de la misma debe ser un consenso efectivo en torno de la aceptación de ciertas premisas. Sólo ese tipo de punto de partida, el hecho de que se argumente a partir de premisas que nuestros interlocutores ya aceptan —o llegarían a aceptar en el curso de la deliberación-, garantiza que nuestra argumentación posea una capacidad efectiva de convencer o de persuadir. En tercer lugar, a diferencia de lo que ocurre en CEE, en CRJ no tiene sentido hacer una distinción entre: 1) justificar que $p$ frente a otros sujetos - donde lograr una justificación apropiada no implica que se alcance una persuasión efectiva sobre ellos-, y 2) convencer, efectivamente, a otros sujetos de que estamos justificados en afirmar que $p$. Desde la perspectiva de CRJ justificar algo frente a otros requiere ser capaces de lograr algún grado de persuasión efectiva sobre ellos ${ }^{37}$. Como sabemos, dada $\mathrm{CEE}$, justificar nuestras creencias frente a otros no presupone ni apelar a premisas que éstos ya acepten ni requiere que haya algún nivel de persuasión efectiva. Así como podría haber persuasión efectiva sin justificación epistémica (porque se apela, por ejemplo, a argumentos falaces pero convincentes) puede haber justificación frente a otro sin persuasión. En cuarto lugar, a diferencia de CEE, CRJ es una concepción contextualista. Es perfectamente posible que un agente esté justificado en creer que $p$ en $\mathrm{C} 1$, un contexto no político, y que deba reconocer que no está justificado en afirmar que $p$ en C2, la arena política. Supongamos, por ejemplo, que un agente primero delibera en $\mathrm{C} 1$ con agentes que comparten su misma formación cultural y sus mismas creencias religiosas; en ese contexto, en que todos parten de premisas compartidas puede justificar frente a sus interlocutores la creencia de que el aborto es un asesinato porque Dios

35 RAWLS, 1973: 580-581. Las cursivas son nuestras. Esta concepción permaneció vigente en toda la obra posterior de RAWLS. Tanto en su artículo «Justice as Fairness: Political not Metaphysical» (1985), como en su libro Justice as Fairness: A Restatement (2001) reitera, sin modificaciones significativas, la misma definición del concepto de justificación ( $c f r$. RAWLS, 1999a: 394, y RAWLS, 2001: 27).

36 RAWLS, 1999a: 394. Como podrá percibirse, la exclusión de la apelación a la verdad como categoría política relevante es, contra lo que supone J. COHEN, esencial para el proyecto del liberalismo político.

37 Partir de premisas compartidas por todas las partes no garantiza que el resultado de la deliberación sea un consenso, por esa razón RAWLS admite que es de esperar que compitan entre sí diversas concepciones políticas liberales de la justicia. Sin embargo, aun cuando no se logre el consenso, todos deben admitir que las distintas propuestas disponen de una justificación plausible. Por supuesto, cada agente creerá que la concepción política de la justicia que suscribe es la que dispone de la mejor justificación. 
da alma al feto en el momento de la concepción. Sin embargo, al pasar a C2, la esfera política, marcada por el hecho del pluralismo, debe deliberar con sujetos que poseen creencias incompatibles con las suyas. Frente a la ausencia de premisas compartidas, y dadas las cargas del juicio, el agente debe reconocer que el persistente desacuerdo de sus interlocutores es una prueba de que ha fallado en justificar sus creencias frente a ellos. El reconocimiento de que en $\mathrm{C} 2$ ha fallado en justificar sus creencias frente a los demás es compatible con la convicción de que sí ha logrado justificarlas en $\mathrm{C} 1$, donde sí existe un trasfondo de experiencias, prácticas y creencias compartidas entre los distintos interlocutores. Como podrá percibirse, dada CRJ, el argumento de RAWLS para explicar las razones por las cuales las doctrinas comprehensivas no pueden constituir una base de justificación de las políticas del Estado, sin que ello implique un cuestionamiento escéptico de las mismas, parece funcionar sin dificultades.

Ahora bien, la apelación a CRJ acarrea una serie significativa de problemas. Por una parte, RAWLS nunca ofrece un argumento que explique por qué deberíamos aceptar CRJ en lugar de CEE como concepción de la justificación política. En cierta forma, esa idea es un axioma de su teoría. Pero ¿por qué deberíamos reconocer que la obligación moral básica de justificar nuestras propuestas políticas frente a los demás sobre la base de razones que no puedan rechazar razonablemente debe ser entendida en términos de CRJ, en lugar de ser entendida en términos de lo que hemos denominado la concepción epistémica estándar? Después de todo, cuando se aprecia la cuestión desde la perspectiva de CEE, la concepción de RAWLS no tiene el estatus de una concepción de la justificación, sino de una concepción de la persuasión. ¿Por qué es esencial, si hemos justificado nuestras creencias frente a los otros en forma apropiada, lograr persuadirlos efectivamente de que se trata de creencias justificadas? CEE y CRJ no son solamente concepciones distintas entre sí, sino que son, como vimos, opuestas e incompatibles en diversos puntos. Este último hecho es problemático en sí mismo, dado que la plausibilidad del liberalismo político no debería depender de la aceptación de una concepción, CRJ, que presupone el rechazo de rasgos básicos del concepto de justificación epistémica, tal como es caracterizado por una influyente tradición dentro de la filosofía. Al hacer esto, el liberalismo político adopta, contra sus propios presupuestos, una posición comprehensiva filosófica profundamente controvertida.

\section{II.}

1.

En esta sección final intentaremos explicar el modo en que el liberalismo político puede superar las objeciones formuladas en la sección I.2, sin incurrir en los problemas que, según acabamos de ver en la sección I.3, involucra la apelación a CRJ, interpretada como una concepción de la justificación de creencias alternativas a CEE.

El punto de partida de nuestra propuesta consistirá en defender la idea de que estar epistémicamente justificado a afirmar que $p$ no implica necesariamente estar justificado a actuar sobre la base de esa creencia en todo contexto. Existen, por supuesto, casos en que las creencias de un agente, junto con sus deseos o metas, constituyen los únicos factores de los que depende la justificación de una decisión. Supongamos que un 
agente planea salir a navegar en un velero durante el fin de semana, pero, por supuesto, otorga prioridad sobre ese deseo al de evitar sufrir un accidente que podría poner en riesgo su vida. Ahora bien, dado ese esquema de deseos, la decisión que finalmente tome el sujeto puede depender enteramente, por ejemplo, de sus creencias acerca del estado del clima. Si se convence, al consultar varios informes meteorológicos, de que va a desatarse una fuerte tormenta el sábado por la tarde, decidirá suspender la excursión. En este caso, estar justificado a creer que $p$ («habrá una fuerte tormenta el sábado») es suficiente para estar justificados a tomar una decisión («suspender la excursión»). Sin embargo, son muy comunes las situaciones que contradicen ese patrón. Un agente puede estar justificado a creer que $p$ y, sin embargo, no estar justificado a actuar sobre la base de esa creencia en un contexto determinado. Como veremos, las razones de ello no tienen que ver con la interacción entre las creencias del agente y sus deseos o metas, sino con la injerencia de factores prácticos adicionales. En ocasiones es posible que el agente deba poner entre paréntesis sus creencias y tomar la decisión basado en otras premisas que pueden, o bien ser diferentes de dichas creencias o, incluso, su directa negación. Imaginemos algunos casos.

Tres individuos deben decidir si invierten sus ahorros en la construcción de un edificio de oficinas. Saben que no es posible calcular con precisión los costos totales que demandará la construcción. Los distintos subcontratistas sólo están en condiciones de darles un costo aproximado que puede variar de acuerdo con subas o bajas futuras del precio de los materiales o con la disponibilidad en el mercado de ciertos insumos alternativos. El costo de cometer un error subestimando el monto de dinero necesario podría ocasionar la pérdida completa de la inversión al quedar la obra inconclusa. Como consecuencia de ello y de la incertidumbre acerca del monto total de dinero que deberá ser invertido, cada individuo basa su decisión de participar en el proyecto en las estimaciones de costos más altas, aun cuando no crea que ellas reflejen la realidad. Cada individuo decide invertir sólo si es capaz de afrontar las estimaciones de costos más elevadas. La situación sería distinta si se les ofreciera a los mismos sujetos una apuesta que premiara al que hiciera la estimación más exacta del costo final de la construcción, en ese caso deberían razonar de un modo diferente y apostar, no por la estimación de costos más alta, sino por aquella que realmente creen más exacta. Después de todo, la consecuencia de errar por elegir un costo superior al real es igual a la de errar por escoger un costo inferior: en ambos casos se pierde la apuesta. En el caso de la decisión de invertir, no se da esa simetría, errar por subestimar el monto de dinero requerido es muy grave, mientras que errar sobreestimando el monto de dinero necesario no acarrea consecuencias significativas ${ }^{38}$.

En este caso la decisión de invertir o abstenerse de hacerlo no depende de las creencias reales de los sujetos acerca del costo total del emprendimiento, sino de premisas que, aunque no son creídas, resultan identificadas como bases más apropiadas para desarrollar el razonamiento en el que se decide el curso de acción a tomar. El factor responsable de que las creencias de los agentes deban ser puestas entre paréntesis es el elevado costo de cometer un error y la asimetría, en relación con las consecuencias prácticas de la acción, que existe entre errar subestimando el monto total requerido por la inversión y errar sobrestimándolo. Dada la inelimi-

38 Este ejemplo es una variación de uno propuesto originalmente por M. BRATMAN (cfr. BRATMAN, 1992: 6). 
nable posibilidad de cometer un error al no tomar la estimación de costos más alta y las consecuencias que tendría ese error, no basta con estar justificado a creer que una estimación más baja es la correcta para estar justificados a tomar la decisión de invertir. En el contexto de la apuesta, donde no existe una asimetría entre errar por subestimación o por sobrestimación de los costos, no hay razones para poner entre paréntesis las creencias de los agentes acerca de los costos reales, por el contrario, lo más razonable es apostar a la luz de dichas creencias. Otro ejemplo estructuralmente similar sería el siguiente.

Dos científicos, A y B, se encuentran trabajando en distintas aplicaciones tecnológicas de una misma teoría, que denominaremos T1. Se trata de una teoría novedosa que cuenta con un número significativo y creciente de defensores dentro de la comunidad científica. Dado que hay disponible muy buena evidencia que avala T1, A y B se encuentran firmemente convencidos de que se trata de la teoría verdadera. Por supuesto, ambos reconocen que en ciencias fácticas la posibilidad de error es ineliminable y que nunca puede ser considerada trivial, no importa lo convencido que se esté de la verdad de una teoría. Hay una diferencia importante entre los proyectos de investigación de A y B. Mientras la investigación de A es inocua en caso de error, un error en el trabajo de $B$, dado el tipo particular de pruebas y experimentos que debe realizar, produciría un daño enorme: miles de personas podrían morir o sufrir daños irreversibles. Supongamos, además, que alertados del peligro, los miembros de la comunidad en la que vive $B$ se oponen a que éste continúe con sus experimentos.

Es plausible sostener que A y B están igualmente justificados, desde una perspectiva epistémica, a creer que T1 es verdadera. Ello se debe a que ambos sujetos poseen la misma evidencia en favor de dicha teoría. Sin embargo, parece haber buenas razones para concluir que mientras en el contexto en que se encuentra A, C1, la creencia de que $\mathrm{T} 1$ es verdadera le ofrece una justificación adecuada para actuar, tal creencia es insuficiente para ofrecer una justificación en el contexto en que se encuentra B, C2. A diferencia de lo que ocurre en $\mathrm{C} 1$, en $\mathrm{C} 2$ el costo del error es altísimo desde una perspectiva moral. El caso de los científicos pone en evidencia, en primer lugar, que estar justificado, desde una perspectiva epistémica a creer que $p$, no implica necesariamente estar justificado a actuar sobre la base de que $p$ en cualquier contexto. Cuando el costo de cometer un error es muy alto y la posibilidad de que tal cosa ocurra no puede ser descartada, aún creencias que poseen una justificación epistémica apropiada y son, consecuentemente, afirmadas con un significativo grado de confianza, pueden no ser suficientes para justificar la toma de una decisión y la subsiguiente realización de acciones.

Existen otros factores, además de los costos o las asimetrías en los costos del error, que explican el hecho de que en muchos contextos de acción las creencias de los agentes no sean las premisas que poseen un peso determinante en sus decisiones. Veamos dos ejemplos:

«Un abogado defensor cree, sobre la base de muy buena evidencia, que su cliente es culpable del crimen del que se lo acusa. Sin embargo, para cumplir con las obligaciones que le impone su función profesional, debe desarrollar la mejor estrategia de defensa posible para que su cliente no sea encontrado culpable por el jurado. Para planear su estrategia debe tomar como premisa la inocencia del acusado, aun cuando no crea en ella». 
«Los miembros del jurado en un juicio penal llegan a convencerse de la culpabilidad de un sujeto acusado de haber cometido un robo. Sin embargo, las únicas evidencias que vinculan al acusado con el delito, a las que los jurados tuvieron ya acceso, deben ser eliminadas porque la defensa logra probar que fueron obtenidas en forma ilegal por la policía. A pesar de sus creencias, cada jurado decide no declarar culpable al acusado porque reconoce que no dispone de la evidencia, válida en el tribunal, requerida para hacerlo. De modo que el jurado se pronuncia, correctamente desde la perspectiva legal, por un veredicto en cuya verdad sus miembros no creen».

En el caso del abogado las premisas sobre la base de las cuales es planeada su acción deben diferir de sus creencias gracias a las obligaciones que éste adquiere como consecuencia de la función social que desempeña. En el caso de los jurados, el contraste entre las creencias de los individuos y las premisas en las que se apoya su decisión depende de la aceptación de las reglas de evidencia vigentes dentro de una institución social determinada: un tribunal penal. En todos los casos que vimos, los sujetos, por diversas razones, deben poner entre paréntesis sus creencias reales, dado que éstas, aun cuando estuviesen justificadas desde una perspectiva epistémica y fuesen verdaderas, resultan inadecuadas para justificar la acción en los contextos específicos en que ésta debe desarrollarse. Ello, como hemos visto también, no implica que los sujetos no puedan mantener sus creencias y actuar a partir de ellas en otros contextos diferentes ${ }^{39}$.

Los casos que acabamos de presentar permiten introducir una distinción conceptual que resulta muy útil para nuestros fines. Se trata de la distinción entre creencia y aceptación (acceptance) ${ }^{40}$. Aceptar que $p$ equivale a tomar la decisión de tratar a dicha proposición, en un contexto específico de deliberación, como verdadera -es decir, ignorar, por el momento y para los fines de la deliberación y subsecuente toma de decisión, la posibilidad de que sea falsa - , aun cuando no se crea realmente en su verdad. Muy frecuentemente el sujeto aceptará, como premisas para sus razonamientos tanto teóricos como prácticos, proposiciones que, además, cree verdaderas ${ }^{41}$; $\sin$ embargo, es importante subrayar que también es posible que acepte proposiciones en cuya verdad no cree $^{42}$. Como vimos, por ejemplo, en el caso de la construcción del edificio de oficinas, los sujetos aceptan como premisa para tomar la decisión de invertir o abstenerse de hacerlo la estimación más alta del costo total del proyecto, no sus creencias acerca de cuál podría ser el costo total real. Un patrón semejante se da en los casos restantes: las premisas de las que dependen las deliberaciones de los agentes no son creídas por ellos, pero son aceptadas, a los fines de la toma de decisión en el con-

39 Por supuesto, existen otro tipo de razones que explican el posible contraste entre las creencias de un agente y las premisas en las que basa sus decisiones en ciertos contextos específicos. BRATMAN, por ejemplo, ha propuesto una serie de casos en los que, además de los mencionados, entran en juego factores como la necesidad de realizar simplificaciones para llegar a una decisión en el tiempo requerido, los requisitos de la cooperación social, la injerencia de relaciones especiales que los sujetos tienen con otros individuos y lo requerido por las precondiciones generales del razonamiento práctico ( $c f r$. BRATMAN, 1992: 5-8).

40 Cfr. Van Fraassen, 1980; Stalnaker, 1984; L. J. Cohen, 1992; Bratman, 1992; Tuomela, 2000; VeLLEMAN, 2000.

${ }^{41}$ Cfr. L. J. CoHEN, 1992: 170.

${ }^{42}$ Cfr. STALnAKER, 1984: 79-81. L. J. CoHEN define «aceptación» en los siguientes términos: «[...] Aceptar la proposición o regla o inferencia de que $p$ es tratar como dado que $p$. Más precisamente, aceptar que $p$ es tener o adoptar una política de considerar (deeming), asumir (positing) o postular (postulating) que $p$-es decir, de incluir esa proposición o regla entre nuestras premisas para decidir qué hacer o qué pensar en un contexto particular, sienta uno o no que es verdad que $p$ 一 (L. J. COHEN, 1992: 4). 
texto en que se encuentran. El científico A puede creer y aceptar T1, mientras que B puede creer en T1 pero no aceptarla como una premisa que justifique la realización del riesgoso experimento que planeaba. El abogado acepta que su cliente es inocente a los fines prácticos de elaborar una estrategia de defensa, aunque no cree en su inocencia. Los jurados ponen entre paréntesis, se abstienen de aceptar las evidencias que prueban que el acusado es culpable y razonan a partir de sus creencias restantes - aquellas que pueden ser objeto de aceptación, es decir, aquellas que pueden ser tomadas como premisas de la deliberación—, las cuales, sin embargo, no permiten emitir un veredicto de culpabilidad.

Existen importantes diferencias entre los actos de aceptación y las creencias. A los efectos de hacer una comparación, presentemos una lista con algunos de los rasgos que habitualmente son considerados característicos de la noción de creencia ${ }^{43}$.

1. Las creencias apuntan a la verdad, ésta constituye su criterio de corrección. Si llegamos a la conclusión de que $p$ no es verdad, y somos agentes cognitivamente razonables, no podemos continuar creyendo que $p$.

2. Las creencias razonables son conformadas por evidencias relativas a aquello que es creído y concernientes a la verdad de lo que es creído. Una creencia es racional si es respaldada por un grado adecuado de evidencia de su verdad ${ }^{44}$. Es irracional creer en contra de la evidencia de la que se dispone.

3. Las creencias no son objeto de control voluntario por parte del agente, éste no decide qué creer. Un agente no puede creer a voluntad que su casa está incendiada si no tiene evidencia de ello, si, por ejemplo, no ve ni humo ni llamas por ninguna parte y no siente olor a quemado; por el contrario, en caso de que se tope con esos indicios concurrentes no podrá evitar creer que se encuentra frente a un incendio.

4. Las creencias son, en un sentido importante, contexto-independientes: un sujeto, en un tiempo determinado, o bien cree en algo o bien no lo cree, pero no puede creer que $p$ en un contexto y que no $p$ en otro. Por ejemplo, un agente no puede creer que el candidato a senador $\mathrm{X}$ es corrupto cuando habla con su esposa y luego, cuando habla con un compañero de trabajo, creer - sin que haya variado la evidencia de la que dispone-, que dicho candidato a senador es honesto ${ }^{45}$. Puede ocurrir que haya razones para mentirle a su compañero de trabajo y decirle, contra sus creencias, que el candidato no es corrupto, pero no puede creer ambas cosas por más que el contexto del diálogo cambie: o cree que el candidato es corrupto o cree que no lo es. Si creemos algo, esa creencia debe perdurar a través de varios contextos, a no ser, por supuesto, que la descartemos como resultado de que ha aparecido en el proceso evidencia contraria a ella. En ese caso, por supuesto, la descartaremos en los distintos contextos en los que tomamos parte.

43 Seguiremos, fundamentalmente, a BRATMAN en esta caracterización ( $c f r$. BRATMAN, 1992: 3-4, y también ENGEL, 1998: 143).

${ }_{44}$ Cfr. BratMan, 1992: 3, y Engel, 1998: 143.

45 ENGEL ofrece un ejemplo similar: «Sería absurdo, o una forma de capricho, decir que los miércoles creo que Hong Kong es una ciudad ruidosa, y los domingos no creo tal cosa. Ciertamente puedo tener las dos creencias si ellas responden a dos fragmentos diferentes de evidencia (por ejemplo, hay muchos autos los miércoles, los cuales no vienen a la ciudad los domingos), pero es una cosa extraña decir tal cosa como una verdad general acerca de Hong Kong. O creo que Hong Kong es ruidoso, o creo que no lo es, punto» (ENGEL, 1998: 143). 
5. Las creencias están sujetas a un ideal de integración o aglomeración. Las personas deberían intentar hacer coherentes y consistentes sus creencias, e integrarlas dentro de un punto de vista global más amplio.

Consideramos ahora los rasgos que caracterizan a los actos de aceptación. En primer lugar, a diferencia de la creencia, la aceptación no apunta a la verdad, dado que, como vimos, los agentes pueden aceptar como premisas de sus razonamientos proposiciones cuya verdad no necesariamente afirman: se puede aceptar que $p$, sin creer que $p$ sea verdadera. En segundo lugar, los factores de los que depende que una proposición sea o no aceptada como premisa de nuestras deliberaciones no son de orden epistémico, sino práctico (la asimetría de riesgos implicada en la situación, el nivel de daño - para los propios intereses del sujeto o para los intereses de otros agentes- esperable en caso de error, consideraciones morales relativas a qué riesgos son aceptables en la acción, obligaciones adquiridas como resultado de desempeñar una función social, etc.) ${ }^{46}$. Desde la perspectiva tradicional, resultaría objetable que nuestras creencias fuesen modeladas por ese tipo de factores prácticos. Las razones para creer que $p$ o abstenerse de hacerlo, para un agente racional, deberían depender exclusivamente de la evidencia de la que éste disponga de la verdad o de la falsedad de que $p$. Sin embargo, aún aceptando esta concepción, parece perfectamente lícito que factores prácticos como los mencionados tengan un impacto significativo en la justificación de nuestras acciones ${ }^{47}$. Decidir cómo vamos a actuar tomando sólo en cuenta consideraciones de orden epistémico - por supuesto, en conjunción con nuestro esquema de deseos o metas- nos convertiría en agentes irracionales desde un punto de vista práctico, incapaces de actuar con prudencia al hacer inversiones, de aceptar reglas especiales de pertinencia de las evidencias - como ocurre con un juicio penal-, o de desempeñar ciertas funciones sociales — como la de abogado defensor- Los actos de aceptación constituyen entonces una pieza fundamental de nuestra racionalidad práctica. En tercer lugar, mientras las creencias son adquiridas por el sujeto de forma predominantemente pasiva — dado que son inducidas, más allá de la voluntad del sujeto, por la evidencia con la que éste entra en contacto-, la aceptación es el resultado de un acto voluntario y deliberado. Los actos de aceptación tienen, como sostiene L. J. COHEN, el estatus de una política que adoptamos frente a nuestras creencias. En ciertos casos decidimos abstenernos de aceptar, es decir, de incluir en el razonamiento que nos lleva a la toma de decisión y a la acción, ciertas creencias que de hecho suscribimos; en otros casos, decidimos aceptar proposiciones en las que no creemos. En cuarto lugar, a diferencia de las creencias, que son normalmente concebidas como independientes del contexto, los actos de aceptación tienen una naturaleza contextual. Por ejemplo, en el caso del juicio penal al que hicimos referencia páginas atrás, los jurados ponen entre paréntesis, no aceptan, la creencia de que el acusado de robo es culpable, dado que depende de una evidencia que debe ser excluida porque fue obtenida ilegalmente por la policía. Ellos continúan creyendo que el acusado cometió el robo, pero deben reconocer que no pueden declararlo

46 Como afirma L. J. COHEN, las razones para aceptar que $p$ pueden ser éticas, profesionales, prudenciales, religiosas, estéticas, y, en general, pragmáticas, en lugar de evidenciales ( $c f r$. L. J. COHEN, 1992: 20).

47 Para autores como L. J. CoHEN, los actos de aceptación no juegan un papel significativo sólo en la justificación de las acciones, sino que también lo hacen en el campo teórico. Dados los intereses del presente trabajo, nos concentraremos principalmente en el papel que juega la aceptación en la justificación de acciones. 
culpable. Ahora bien, supongamos que en otro contexto, meses después del juicio, el acusado le propone a uno de los sujetos que fueron miembros del jurado realizar un negocio. En ese nuevo contexto el ex jurado puede decidir rechazar la oferta basado en que cree y acepta que el individuo que le propone el negocio ha tenido en el pasado conductas deshonestas: que ha cometido un robo. Si bien las creencias deberían mantenerse estables en caso de no variar la evidencia en los distintos contextos, los actos de aceptación pueden variar, para ajustarse a los factores prácticos que entran en juego en cada caso. En quinto lugar, el ideal de integración coherente dentro de un punto de vista más amplio o global que rige en el caso de las creencias no se aplica del mismo modo a los actos de aceptación, dado que éstos, como vimos, dependen de factores prácticos contextuales. Retomemos el último ejemplo. El hecho de que cada jurado deba, como consecuencia de factores prácticos ${ }^{48}$, abstenerse de aceptar en el juicio su creencia de que el acusado ha cometido el robo del que se lo acusa no lo compromete a abstenerse, como resultado de la necesidad de satisfacer un requisito de coherencia, de aceptar esa creencia en otros contextos en los cuales las referidas razones prácticas están ausentes. Si, como hemos supuesto, luego del juicio el acusado le propone participar de un negocio a uno de los ex jurados, éste es libre, en ese nuevo contexto, de realizar un acto de aceptación distinto del que hizo durante el juicio y tomar la creencia de que el sujeto ha cometido un delito como premisa de su decisión, en este caso, de rechazar la propuesta de negocios.

\section{2.}

Las consideraciones precedentes ofrecen al liberalismo político las herramientas conceptuales necesarias para superar las objeciones que fueron presentadas en la sección I.2, evitando las dificultades que acarrea la apelación a una concepción práctica de la justificación de creencias como la introducida por RAWLS, que fueron examinadas en la sección I.3. Desarticular las objeciones referidas supone dar dos pasos fundamentales. En primer lugar, debemos dejar de ver a las concepciones políticas de la justicia, primariamente, como conjuntos de creencias y concebirlas como constituidas, en sus elementos fundamentales, por actos de aceptación ${ }^{49}$. Como consecuencia de ello, en segundo lugar, la idea de justificación pública debe ser reinterpretada. CRJ no debe ser vista como un proceso argumentativo cuya meta es la justificación de creencias a partir

${ }^{48}$ En ese caso, la violación de las reglas de admisibilidad de evidencia que rigen en el tribunal.

49 Creemos que esta propuesta permite articular conceptualmente, en forma consistente y clara, la idea de RAWLS de que la justificación política, más que requerir que todos los involucrados tomen como punto de partida de su argumentación premisas que reconozcan como verdaderas, exige que todos tomen como punto de partida premisas que reconozcan «como públicamente aceptables para el propósito de establecer un acuerdo realizable sobre las cuestiones fundamentales de la justicia política», dado que «el propósito de justicia como imparcialidad, como una concepción política, es práctico y no metafísico o epistemológico: ésta se presenta a sí misma no como una concepción de la justicia que es verdadera, sino como una que puede servir como base de un acuerdo político informado y voluntario entre ciudadanos concebidos como personas libres e iguales» (RAWLS, 1999a: 394). La posición del liberalismo político, según consideramos que debería ser interpretada, es que los ciudadanos, crean o no en la verdad de la concepción política de la justicia, deben aceptarla, esto es, decidir convertirla en premisa de sus deliberaciones políticas. Esa decisión — que no es en sí misma otra cosa que una política - no dependerá de factores de orden epistémico, sino de factores práctico-morales asociados con la idea de persona razonable. 
de una serie de premisas compartidas que tienen, también, el estatus de creencias, como parece implicar una lectura estándar del planteo de RAWLS. La meta del proceso de justificación pública es la justificación de acciones (las políticas del Estado), no de creencias, y parte fundamental de ese proceso de justificación depende de premisas que tienen el estatus de actos de aceptación.

Según vimos en la sección I.2, el rechazo rawlsiano de las doctrinas comprehensivas como bases apropiadas de justificación de las políticas fundamentales del Estado, parece implicar la asunción de una posición escéptica respecto de dichas doctrinas. Ello se debe a que RAWLS sostiene que, dadas las cargas del juicio, no es posible distinguir entre creencias comprehensivas genuinas y espurias, es decir, entre creencias comprehensivas que pueden ser afirmadas, en forma justificada, como verdaderas, y creencias comprehensivas que tienen un estatus puramente subjetivo. Uno de los rasgos fundamentales del argumento de RAWLS consiste en distinguir entre creencias que son susceptibles de una justificación pública - las concepciones políticas de la justicia- y creencias que no lo son - las doctrinas comprehensivas religiosas, filosóficas o morales- Sin embargo, a la luz de CEE, negar que ciertas creencias - las comprehensivas- dispongan de una justificación pública equivale a negar que dispongan tout court de una justificación epistémica apropiada, dado que toda justificación epistémica apropiada es por naturaleza pública. Esto implica adoptar una posición escéptica respecto de las doctrinas comprehensivas religiosas, filosóficas o morales.

Ahora bien, si se adopta la propuesta esbozada líneas atrás, la situación es diferente. Afirmar que las doctrinas comprehensivas no son una base adecuada de justificación de las políticas fundamentales del Estado no implicaría afirmar que no puede distinguirse públicamente entre creencias comprehensivas genuinas y espurias, ni que, consecuentemente, las creencias comprehensivas no son susceptibles de una justificación epistémica apropiada. Desde la perspectiva que estamos proponiendo, afirmar que las doctrinas comprehensivas no son una base adecuada de justificación de las políticas fundamentales del Estado equivale a decir que las creencias comprehensivas no pueden, dadas las cargas del juicio, dar lugar a actos de aceptación compartidos por todos los sujetos afectados. Recordemos que, a diferencia de las creencias, los actos de aceptación surgen de una decisión voluntaria, son una política que el sujeto es libre de implementar o no implementar. No resulta plausible esperar que las doctrinas comprehensivas suministren una base compartida de justificación, porque no podemos esperar que los sujetos acepten libremente creencias irreconciliables con las propias o que, en muchos casos, ni siquiera son capaces de comprender o interpretar cabalmente. Por el contrario, las concepciones políticas de la justicia, por basarse en prácticas, experiencias y creencias compartidas, pueden dar lugar, libremente, a los mismos actos de aceptación, es decir, a que los sujetos acepten las mismas premisas como bases de justificación de la acción en un contexto específico: la arena política. La exigencia de que las premisas en las que se basa la justificación de la acción del Estado puedan ser libremente aceptadas por todos los afectados no es una exigencia de orden epistémico, no es una condición necesaria para que una creencia pueda ser públicamente justificada (es decir, justificada en forma apropiada desde una perspectiva epistémica), es una exigencia de orden moral que deriva de la consideración de los ciudadanos como agentes morales libres e iguales, y quizá, en última instancia, de las implicaciones de concebir, como lo hace RAWLS, a la sociedad como un sistema equitativo de coopera- 
ción entre personas libres e iguales ${ }^{50}$. Estas ideas morales funcionan como una presión práctica que debe moldear, no las creencias — comprehensivas - de los agentes, sino los actos de aceptación a partir de los cuales éstos justifican sus acciones unos frente a los otros.

Ahora bien, el hecho de que ciertas creencias - las doctrinas comprehensivas- no puedan ser objeto de actos de aceptación suscritos por todos los individuos que forman parte de un contexto de deliberación y acción: el político, no implica que dichas creencias no puedan contar con una justificación epistémica apropiada. Según vimos, los miembros del jurado, aun cuando no puedan aceptar en el contexto del juicio las evidencias que apuntan a la culpabilidad del acusado y no estén en condiciones de tomar la decisión de condenarlo, pueden estar perfectamente justificados, desde una perspectiva epistémica, a creer que éste ha cometido efectivamente el crimen. No están justificados a actuar sobre la base de sus creencias en un contexto determinado, pero ello no implica que no estén justificados a creer y actuar sobre la base de ellas en otros contextos. Los inversores del ejemplo pueden continuar creyendo que el costo del edificio será menor que el que tienen en cuenta a la hora de evaluar si disponen o no de dinero suficiente como para poder decidir participar del proyecto. De igual modo, el hecho de que los ciudadanos admitan que las doctrinas comprehensivas no resultan adecuadas para ser tomadas como las premisas de las que depende la justificación de la acción del Estado en la esfera política no implica que no puedan continuar creyendo, quizá en forma justificada desde una perspectiva epistémica, en la verdad o corrección de dichas doctrinas. También es perfectamente plausible que los sujetos actúen tomando sus creencias comprehensivas como premisas en otros contextos de acción no políticos, así como los jurados del ejemplo pueden decidir evitar, luego del juicio, hacer negocios con el acusado, dado que lo consideran un criminal, o así como el inversionista puede hacer una apuesta acerca del monto de dinero que será necesario para completar la construcción del edificio, tomando como premisas sus creencias reales acerca del costo del proyecto.

Podemos concluir que al concebir las concepciones políticas de la justicia como constituidas, fundamentalmente, por actos de aceptación, se evitan las consecuencias escépticas que parece involucrar el planteo original de RAWLS. Otra conclusión a la que puede arribarse es que, al concebir la idea de justificación pública como un proceso cuya meta final es la justificación de acciones, no de creencias, en el cual juegan un papel decisivo actos de aceptación, se disuelve la tensión que existía en el planteo de RAWLS entre la idea de justificación pública (CRJ) y la noción tradicional de justificación epistémica de una creencia (CEE). El requisito de que los agentes tomen como punto de partida premisas compartidas no es exigido como una condición necesaria para la justificación de creencias, sino como un requisito para la justificación de acciones frente a otros sujetos, dado el supuesto adicional de que los sujetos reconocen una obligación moral de ofrecer tales justificaciones sobre la base de razones que puedan ser libremente suscritas por sus interlocutores ${ }^{51}$. El hecho de que un agente falle en justificar sus propuestas de acción frente a otro, porque sus argumentos apelan a expe-

50 Cfr. RAWLS, 1993: 15-22.

51 Después de todo, la idea scanloniana que, según RAWLS, se encuentra en el corazón del concepto de persona razonable, estipula que tenemos un compromiso moral básico de justificar, no nuestras creencias, sino 
riencias o creencias que los demás no están dispuestos a aceptar libremente como bases de toma de decisión (es decir, como términos equitativos de cooperación), no dice nada acerca de la calidad epistémica de las creencias del sujeto ni implica que haya fallado en ofrecer una justificación epistémica apropiada de su punto de vista frente a sus interlocutores. Si uno de los jurados del ejemplo decidiera votar la condena del acusado aun cuando debe reconocer que lo motiva su acceso a evidencia que, dadas las reglas del tribunal, no puede formar parte de la toma decisión, su conducta sería cuestionable, habría fallado en justificar su acción. Ello no implicaría, sin embargo, que haya fallado en justificar su creencia de que el acusado es culpable. Según hemos visto, estar justificado a creer que $p$ y a actuar sobre la base de aceptar que $p$ en un contexto determinado son cosas distintas. Así como en un tribunal rigen ciertas reglas de admisión de evidencia — que no están basadas en consideraciones epistémicas, sino práctico-morales-, desde la perspectiva del liberalismo político, en la política democrática rige la exigencia — también práctico-moral— de que la justificación de las políticas fundamentales del Estado debe basarse en evidencias y formas de razonar efectivamente accesibles para todos los afectados, es decir, en premisas compartidas, porque de lo contrario no se respetaría la igualdad de las personas ni se podría llegar a un acuerdo voluntario acerca de la legitimidad de dichas políticas. Éste no es, por supuesto, un requisito que se aplica a la justificación de creencias, sino a la justificación de acciones. Si lo fuera, entraría en tensión con CEE, dado que factores prácticos, de orden moral, adquirirían prioridad sobre consideraciones puramente epistémicas. Como hemos visto, en la justificación de acciones, a diferencia de lo que ocurre en la justificación de creencias desde una perspectiva tradicional, la injerencia de factores prácticos como los mencionados es perfectamente aceptable. Por otra parte, aunque la justificación de acciones posee un carácter contextual, ello no implica cuestionar el estatus contexto-independiente de CEE. El hecho de que en el contexto del juicio los jurados no estén justificados a actuar sobre la base de la evidencia que incrimina al acusado y de que en otros contextos, fuera del tribunal, sí puedan utilizar esas evidencias para justificar sus decisiones, es perfectamente compatible con el reconocimiento de la idea de que la justificación epistémica de sus creencias es no contextual: es decir que, si están justificados a creer que $p$ en un contexto, lo están en todos. Como sabemos, el hecho de que un sujeto no pueda aceptar que $p$ en un contexto -es decir, utilizar $p$ como premisa de sus deliberaciones orientadas a tomar una decisión y actuar en consecuencia - es perfectamente compatible con que el sujeto crea, en general, que es verdad que $p$. Aceptar el carácter contextual de la justificación de las acciones no implica cuestionar el carácter contexto-independiente de la justificación epistémica de creencias. Por supuesto, la situación es distinta cuando se concibe la justificación política, no como una forma de justificación de acciones en la que juegan un papel central actos de aceptación, sino como una concepción de la justificación de creencias. Si se interpreta de esa manera el proyecto del liberalismo político, éste involucra efectivamente la apelación a una concepción contextualista incompatible con CEE. Sin embargo, según hemos intentado demostrar, no hay por qué sostener esa interpretación de CRJ.

«nuestras acciones frente a otros sobre bases que ellos no pudieran rechazar razonablemente» (RAWLS, 1993: $49, n)$. La cursiva es nuestra. 
3.

Para terminar, quisiéramos señalar que la propuesta que estamos defendiendo tiene una ventaja adicional: torna al liberalismo político aceptable para muchos escépticos morales y para aquellos que consideran que los principios de justicia, como el resto de las ideas y juicios morales, son meramente la expresión de nuestras emociones. Como sostiene S. FreEMAn, hacer el liberalismo político aceptable para los escépticos morales es una meta importante para RAWLS y constituye una de las razones por las que el autor sostiene que el criterio de corrección de la concepción política de la justicia no debe ser la verdad, sino la razonabilidad ${ }^{52}$. Ahora bien, al caracterizar la idea rawlsiana de que las concepciones políticas de la justicia deben ser independientes (freestanding), FREEMAN sostiene que el liberalismo político asume que «ciudadanos libres e iguales comparten ciertas creencias morales/políticas razonables, a pesar de sus muchas diferencias». La concepción política, continúa el autor, «empieza desde esas creencias razonables compartidas, sin inquirir acerca de su valor de verdad (ellas podrían no tener ninguno si el escepticismo moral es correcto), o en sus orígenes filosóficos, psicológicos o sociales» ${ }^{53}$. Ahora bien, afirmar, como lo hace FREEMAN siguiendo el modo usual de hablar de RAWLS, que la concepción política de la justicia parte de «creencias» resulta problemático si se quiere sostener también que el problema de la verdad de dichas creencias es puesto entre paréntesis. Como hemos visto, las creencias apuntan a la verdad, no se puede mantener una creencia genuina sin afirmar que es verdadera. Esto parece dar apoyo a las tesis de J. COHEN de que el concepto de verdad es inescapable y de que el intento rawlsiano por eliminarlo del proceso de justificación política es irrealizable: el uso de la noción de creencia reintroduce la verdad como su criterio de corrección ${ }^{54}$. Por el contrario, describir, adoptando la propuesta que estamos defendiendo, el punto de partida de la concepción política de la justicia como un conjunto de actos de aceptación resuelve el problema. Aunque es perfectamente posible y frecuente que aceptemos como premisas de nuestras decisiones proposiciones en las que también creemos, es también posible, como lo muestran los ejemplos introducidos páginas atrás, aceptar como premisas fundamentales de nuestros razonamientos prácticos, proposiciones en cuya verdad no creemos. De modo que los escépticos morales y los emotivistas podrían suscribir sin inconvenientes la concepción política de la justicia caracterizada del modo que estamos proponiendo hacerlo: no estarían comprometidos

52 Según FrEeman, no debe pensarse que la posibilidad de que los escépticos morales razonables desarrollen razonamientos morales constituye una paradoja: «Aunque los escépticos morales rechazan la verdad moral, continúan aceptando (a menos que sean nihilistas) que los juicios morales son más o menos razonables. Ser un escéptico moral no nos descalifica para ser razonables, o para embarcarnos en el razonamiento político acerca de la justicia» (FREEMAN, 2007: 356.) Como continúa afirmando el autor en una nota que sigue al párrafo citado: «Los filósofos que defienden el escepticismo moral normalmente insisten en que su escepticismo no tiene efecto sobre su razonamiento moral o su sinceridad moral. Más aún, los académicos en las escuelas de leyes americanas frecuentemente se declaran positivistas morales y legales que niegan el valor de verdad de las demandas de justicia; aun así, como abogados, razonan dentro del marco del Derecho consuetudinario (common law), instituido por el poder legislativo (statutory law) y constitucional, incluyendo los conceptos morales que las leyes emplean con frecuencia (como persona razonable, debido cuidado, igual protección, debido proceso, etc.), y creen que las conclusiones legales son más o menos razonables y justificadas, dada la sofisticada estructura del razonamiento legal» (FREEMAN, 2007: 508-509, $n$ 13).

53 FREEMAN, 2007: 355.

54 Cfr. COHEN, 2009: 13. 
a reconocerla como verdadera, sino como una base práctica de acuerdo político operativa en el marco que ofrecen sociedades marcadas por el hecho del pluralismo.

Por otra parte, es interesante notar que la propuesta de J. COHEN de reintroducir, contra la expresa posición de RAWLS, el concepto de verdad dentro de la justificación política tiene un efecto contrario, en este aspecto, a la propuesta que estamos defendiendo. Si, como dice COHEN, «preocuparse por la justicia, como la concepción política indica, requiere preocuparse por la verdad acerca de la justicia» ${ }^{55}$, la empresa del liberalismo político resultará necesariamente inaceptable para escépticos morales y emotivistas. El hecho de que J. COHEN apele a un supuesto concepto «político» de verdad no cambia en nada la situación, porque aunque éste pudiera permitir eludir las controversias filosóficas más profundas acerca de cómo concebir el concepto de verdad, continúa presentando muchos de los rasgos que rechazan tanto escépticos como emotivistas. Consideremos un ejemplo. La concepción política de la verdad de COHEN incluye una noción de correspondencia. Según el autor: «las creencias verdaderas presentan las cosas como son ("dicen acerca de lo que es que es y de lo que no es que no es"), y en ese sentido no controversial corresponden con cómo las cosas son, aunque ello no agregue (o niegue) que tales creencias presentan las cosas como realmente son en sí mismas, en forma determinada e independiente de la mente» ${ }^{56}$. Aunque esta definición fuese realmente «no controversial», la idea de que los juicios morales tienen el estatus descriptivo que supone la noción de correspondencia propuesta por el autor, resultará inaceptable para muchos. Consideremos el caso clásico del emotivismo. Desde esta perspectiva, la función primordial de los juicios morales no es describir o dar información acerca de alguna cosa, no tiene nada que ver con «presentar las cosas como son», sino con crear una influencia, inducir a los sujetos a actuar y a sentir ciertas emociones ${ }^{57}$. El concepto de verdad propuesto por COHEN parece suficientemente controvertido como para concluir que falla en poseer el estatus político al que aspira.

\section{BIBLIOGRAFÍA}

BonJour, L., 1985: The Structure of Empirical Knowledge, Cambridge, Mass., Harvard University Press.

Bratman, M. E., 1992: «Practical Reasoning and Acceptance in a Context», Mind, núm. 101, $1-15$.

Cohen, L. J., 1992: An Essay on Belief and Acceptance, Oxford, Clarendon Press.

Cohen, J., 2009: «Truth and Public Reason», Philosopby E Public Affairs, núm. 1, 2-42.

Engel, P. (ed.), 1998: «Believing, Holding True, and Accepting», Philosophical Explorations, I, 2, 140-151.

FreEman, S., 2007: Rawls, London, Routledge.

FumerTon, R., 2002: «Theories of Justification», en P. K. Moser (ed.), The Oxford Handboock of Epistemology, Oxford, Oxford University Press.

\footnotetext{
55 Cohen, 2009: 42.

56 COHEN, 2009: 27.

57 Cfr., por ejemplo, Stevenson, 1937.
} 
LARMORE, Ch., 1996: The Morals of Modernity, Cambridge, Cambridge University Press.

RAwLS, J., 1973: A Theory of Justice, Cambridge MA, The Belknap Press of Harvard University Press.

- 1993: Political Liberalism, New York, Columbia University Press.

- 1999: The Law of Peoples with «The idea of Public Reason Revisited», Cambridge Mass., Harvard University Press

- 1999a: Collected Papers, en S. Freeman (ed.), Cambridge, Mass., Harvard University Press.

- 2001: Justice as Fairness: A Restatement, Cambridge, Mass., Cambridge University Press.

RAz, J., 1990: «Facing Diversity: The case of Epistemic Abstinence», Philosophy E Public Affairs, núm. 19, 3-46.

- 1998: «Disagreement in Politics», The American Journal of Jurisprudence, núm. 43, 25-52.

StalnaKer, R., 1984: Inquiry, Cambridge, Mass., The MIT Press.

Stevenson, C. L., 1937: «The Emotive Meaning of Ethical Terms», Mind, núm. 46, 14-31.

TuOmela, R., 2000: «Belief versus Acceptance», Philosophical Explorations, núm. 2, 22-157.

VAn FraAssen, B. C., 1980: The scientific image, Oxford, Oxford University Press.

Velleman, J. D., 2000: The possibility of practical reason, Oxford, Clarendon Press.

Wenar, L., 1995: «Political liberalism: an internal critique», Ethics, núm. 106, 32-62. 